\title{
Differential transcriptional regulation of the NANOG gene in chicken primordial germ cells and embryonic stem cells
}

Hee Jung Choi ${ }^{1}$, So Dam Jin ${ }^{1}$, Deivendran Rengaraj ${ }^{1}$, Jin Hwa Kim', Bertrand Pain ${ }^{2}$ and Jae Yong Han ${ }^{1,3^{*}}$ (D)

\begin{abstract}
Background: NANOG is a core transcription factor (TF) in embryonic stem cells (ESCs) and primordial germ cells (PGCs). Regulation of the NANOG gene by TFs, epigenetic factors, and autoregulatory factors is well characterized in ESCS, and transcriptional regulation of NANOG is well established in these cells. Although NANOG plays a key role in germ cells, the molecular mechanism underlying its transcriptional regulation in PGCs has not been studied. Therefore, we investigated the mechanism that regulates transcription of the chicken NANOG (cNANOG) gene in PGCS and ESCs.

Results: We first identified the transcription start site of CNANOG by $5^{\prime}$-rapid amplification of CDNA ends PCR analysis. Then, we measured the promoter activity of various $5^{\prime}$ flanking regions of cNANOG in chicken PGCs and ESCs using the luciferase reporter assay. CNANOG expression required transcriptional regulatory elements, which were positively regulated by POU5F3 (OCT4) and SOX2 and negatively regulated by TP53 in PGCs. The proximal region of the CNANOG promoter contains a positive transcriptional regulatory element (CCAAT/enhancer-binding protein (CEBP)-binding site) in ESCs. Furthermore, small interfering RNA-mediated knockdown demonstrated that POU5F3, SOX2, and CEBP played a role in cell type-specific transcription of CNANOG.
\end{abstract}

Conclusions: We show for the first time that different trans-regulatory elements control transcription of CNANOG in a cell type-specific manner. This finding might help to elucidate the mechanism that regulates CNANOG expression in PGCS and ESCs.

Keywords: Chicken, Embryonic stem cells, NANOG gene, Primordial germ cells, Regulatory elements

\footnotetext{
* Correspondence: jaehan@snu.ac.kr

'Department of Agricultural Biotechnology and Research Institute of

Agriculture and Life Sciences, Seoul National University, Seoul 08826, South

Korea

${ }^{3}$ Institute for Biomedical Sciences, Shinshu University, Minamiminowa,

Nagano 399-4598, Japan

Full list of author information is available at the end of the article
}

(c) The Author(s). 2021 Open Access This article is licensed under a Creative Commons Attribution 4.0 International License, which permits use, sharing, adaptation, distribution and reproduction in any medium or format, as long as you give appropriate credit to the original author(s) and the source, provide a link to the Creative Commons licence, and indicate if changes were made. The images or other third party material in this article are included in the article's Creative Commons licence, unless indicated otherwise in a credit line to the material. If material is not included in the article's Creative Commons licence and your intended use is not permitted by statutory regulation or exceeds the permitted use, you will need to obtain permission directly from the copyright holder. To view a copy of this licence, visit http://creativecommons.org/licenses/by/4.0/. The Creative Commons Public Domain Dedication waiver (http://creativecommons.org/publicdomain/zero/1.0/) applies to the data made available in this article, unless otherwise stated in a credit line to the data. 


\section{Background}

Gene transcription is mainly regulated by transcription factors (TFs) that bind to specific DNA sequences (called motifs) located in the promoter regions of genes [1]. Many TFs contribute to tissue- and cell type-specific gene transcription according to their recognition specificity [2-4]. In addition, TFs generally initiate and guide cell fate such as lineage progression and control the stability of cell differentiation [5]. Therefore, identification of regulatory elements within the promoter region is considered crucial to understand the mechanism underlying transcriptional regulation in specific cell types. A germ cell-specific gene regulatory network is required to maintain the unique properties of primordial germ cells (PGCs) for transmission of genetic information to the next generation [6]. Many studies have investigated germ cell-specific gene promoters to understand their regulatory mechanisms. In many species, germ cells have a unique mechanism of transcription initiation that uses alternate forms of core promoter elements [7-10]. Also, germ cells reorganize different type of core promoter TFs under the control of germ cell-specific TFs during germ cell differentiation [11-13].

In mammals, core TFs such as NANOG, OCT4, and SOX2 control maintenance of pluripotency. Core TFs play an important role in establishing control of gene expression programs that define the identity of embryonic stem cells (ESCs) [14-16]. In particular, the NANOG gene is important for acquisition of pluripotency by ESCs and embryonic germ cells (EGCs) [17-19]. Several earlier studies identified the regulatory elements of NANOG that are required to maintain the self-renewal and pluripotency of ESCs [20-22]. The major regulators of NANOG expression are Octamer- and Sox-binding elements present at the upstream of transcription start site (TSS) in its promoter region, and these elements are positively regulated by binding of OCT4 and SOX2 in ESCs [20, 23]. Direct binding of ZFP143 to the proximal region of the NANOG promoter regulates NANOG expression by modulating OCT4 binding [24]. In addition, TF-binding cis-regulatory elements of NANOG, including SP1/SP3-, SALL4-, and BRD4-binding sites, have been identified as positive regulators [25-27]. On the other hand, P53-binding sites negatively regulate NANOG expression to induce differentiation of ESCs [28]. Therefore, regulation of NANOG expression plays a critical role in determining the fate of pluripotent cells.

PGCs express several pluripotency-related TFs such as NANOG, POU5F3, and SOX2, and their expression controls transcription of germness-related genes in these cells [11, 29]. NANOG plays an essential role during early germ cell development as a key TF required for the formation of PGCs and maintenance of early germ cells [30, 31]. NANOG-deficient PGCs reportedly undergo apoptotic death [32]. It was recently reported that NANOG regulates PGC-specific epigenetic programming and global histone methylation [33, 34]. NANOG is evolutionarily conserved in mammals and most of the lower vertebrate species, including chicken. In particular, NANOG orthologs from chicken, zebrafish, and axolotl are highly conserved [35-37]. Similar to mammals, NANOG is crucial to maintain pluripotency and self-renewal of chicken ESCs [35]. NANOG is expressed during chicken intrauterine embryonic development and is exclusively expressed in PGCs from Hamburger and Hamilton stage 5 (HH5) to HH8. Therefore, NANOG is also important to maintain pluripotency and cell proliferation in chicken intrauterine embryos and PGCs $[31,35,38]$.

Despite the exclusive expression of NANOG in chicken PGCs, the molecular mechanism that regulates its transcription in these cells has not been fully clarified. This study investigated enhancers and suppressors of the proximal promoter region of the chicken NANOG ( $c N A$ $N O G)$ gene in PGCs and ESCs. Furthermore, we investigated transcriptional control of $c N A N O G$ expression via trans-regulatory elements and TFs, which are important for its cell type-specific expression.

\section{Methods \\ Experimental design, animals, and animal care}

This study investigated the cis- and trans-regulatory elements that are important for modulating transcription of the NANOG gene in chicken PGCs using the dual luciferase assay and transcriptome analysis. The management of White Leghorn (WL) chickens was approved by the Institute of Laboratory Animal Resources, Seoul National University, Korea (SNU-190401-1-1). The chickens were housed according to standard procedures at the University Animal Farm, Seoul National University, Korea.

\section{5' Rapid amplification of cDNA ends (5'-RACE) PCR analysis}

To determine the TSS of the cNANOG gene (Gene ID: 100272166), 5'-RACE PCR was performed using a GeneRacer Kit (Invitrogen, Carlsbad, CA, USA) following the manufacturer's instructions. Gene Racer RNA Oligo-ligated mRNA was reverse-transcribed into cDNA. Single-stranded cDNA served as the template in nested $5^{\prime}$-RACE PCR using the GeneRacer 5' Primer and reverse gene-specific primers (GSPs). The cNANOG reverse GSP was 5'-GTC TGC AGT AGG GCT AGT GGC AGA GTC T-3'. The RACE products were identified by DNA sequencing analysis. To confirm the quality of adapter-ligated RNA, 5'-RACE PCR was performed with a chicken $\beta$-actin reverse GSP, which was 872 bp in size and contained $828 \mathrm{bp}$ of $\beta$-actin and $44 \mathrm{bp}$ of the GeneRacer RNA Oligo. 
Table 1 List of primer sequences used to clone the NANOG promoter

\begin{tabular}{|c|c|}
\hline Primer name & Primer sequence $\left(5^{\prime} \rightarrow 3^{\prime}\right)$ \\
\hline cNANOG - 3550 bp_F & AAGCTTTGTCCTITTCTTGACC \\
\hline cNANOG - 3375 bp_F & CTGGAGTCAAGGGCTGTGG \\
\hline cNANOG - 3154 bp_F & TGGGCCCCTCGTTACAGCT \\
\hline cNANOG - 2928 bp_F & CCAGCAGTACAAGCTCCGAA \\
\hline cNANOG - 1988 bp_F & GCGACACGTGGAACA \\
\hline cNANOG - 945 bp_F & CATGGGGGTGTCTGCTC \\
\hline cNANOG - 627 bp_F & CTTCTITGTGCTCCTCC \\
\hline cNANOG - 442 bp_F & CTGCAGTCTGCAATGC \\
\hline cNANOG - 407 bp_F & AATGTCCCGGGGGGGTCTCTGG \\
\hline CNANOG - 377 bp_F & CCATTCTTTGTACTTGGGTGGGGACCGATGAG \\
\hline cNANOG - 312 bp_F & CGAGGGCGGGGGTGCCAGCCCAG \\
\hline cNANOG - 250 bp_F & CTGCAGTCTGCTCCTCC \\
\hline cNANOG - 210 bp_F & CTGCAGTCTGCAATGC \\
\hline cNANOG - 170 bp_F & CCAAAGGGGGAAGCTGC \\
\hline cNANOG - 130 bp_F & ACTCTCCGAATATCCCCATAGC \\
\hline cNANOG - 69 bp_F & TCGTGACAATCTCTTG \\
\hline cNANOG promoter_R & GGTCGGGACGACACCT \\
\hline
\end{tabular}

\section{Construction of NanoLuc luciferase expression vectors derived from the CNANOG promoter}

To construct NanoLuc luciferase expression vectors, the $5^{\prime}$ flanking region of the $c N A N O G$ gene was amplified using genomic DNA extracted from adult chicken blood and inserted into the pGEM-T Easy vector (Promega, Madison, WI, USA). Primer sets were used to clone differently sized fragments of the $c N A N O G$ promoter (Table 1). Then, different lengths of the $5^{\prime}$ upstream region of the $c N A N O G$ gene were inserted between the $K p n I$ and $X h o I$ sites of the pNL1.2 vector (Promega).

\section{Luciferase reporter assay}

The Nano-Glo Dual Reporter Assay System (Promega) was used to assess $c N A N O G$ promoter activity. Prepared cells were seeded in a 96-well plate and co-transfected with the pGL4.53 firefly luciferase (Fluc) and pNL1.2 (NlucP/cNANOG RE) NanoLuc luciferase (Nluc) plasmids using Lipofectamine 2000 (Invitrogen). After transfection for $24 \mathrm{~h}$, cells were lysed with lysis buffer containing Fluc substrate. Fluc signals were then quenched, followed by reaction with Nluc substrate. Signals in arbitrary units (AU) of Nluc and Fluc were measured using a luminometer (Glomax-Multi-Detection System; Promega). Promoter activities were calculated by determining the ratio of Nluc/Fluc signals in AU. pNL1.2, an empty vector, was used as a negative control. All reporter assays were repeated at least three times.
Culture of chicken PGCs, ESCs, and DF-1 cells

WL PGCs were maintained and sub-passaged in KnockOut DMEM (Thermo Fisher-Invitrogen, USA) supplemented with 20\% fetal bovine serum (Hyclone, South Logan, UT, USA), 2\% chicken serum (MilliporeSigma, Burlington, MA, USA), $1 \times$ nucleosides (MilliporeSigma), $2 \mathrm{mmol} / \mathrm{L} L$-glutamine, $1 \times$ nonessential amino acids, $\beta$-mercaptoethanol, $10 \mathrm{mmol} / \mathrm{L}$ sodium pyruvate, $1 \times$ antibiotic-antimycotic (ABAM; Thermo Fisher-Invitrogen), and $10 \mathrm{ng} / \mathrm{mL}$ human basic fibroblast growth factor (MilliporeSigma). PGCs were sub-cultured onto mitomycin-inactivated mouse embryonic fibroblasts at an interval of 5-6 d via gentle pipetting.

Chicken ESCs were generously provided by Dr. Bertrand Pain (INSERM-INRAE). These cells were maintained and sub-passaged as previously described [39]. Briefly, ESCs were cultured in $50 \mathrm{~mL}$ of DMEM/F12 (GIBCO, Grand Island, NY, USA) supplemented with $10 \%$ fetal bovine serum (Hyclone), $1 \times$ nonessential amino acids, $10 \mathrm{mmol} / \mathrm{L}$ sodium pyruvate, $\beta$-mercaptoethanol, $1 \times$ ABAM (Thermo Fisher-Invitrogen), $5 \mathrm{ng} / \mathrm{mL}$ insulin-like growth factor 1,1 $\mathrm{ng} / \mathrm{mL}$ stem cell factor, $1 \mathrm{ng} / \mathrm{mL}$ interleukin $6,1 \mathrm{ng} / \mathrm{mL}$ soluble interleukin 6 receptor $\alpha$, and $1000 \mathrm{U} / \mathrm{mL}$ human leukemia inhibitory factor. ESCs were sub-cultured onto mitotically inactivated STO cells.

Chicken DF-1 cells (CRL-12203; American Type Culture Collection, USA) and chicken embryonic fibroblasts (CEFs) were cultured as negative controls. Chicken DF-1 cells were maintained and sub-passaged in DMEM (Hyclone) supplemented with $10 \%$ fetal bovine serum (Hyclone) and $1 \times$ ABAM (Thermo Fisher-Invitrogen). CEFs were derived from 6-day-old WL embryos and maintained in DMEM (Hyclone) supplemented with $10 \%$ fetal bovine serum (Hyclone) and $1 \times$ ABAM (Thermo Fisher-Invitrogen). All chicken cells (PGCs, ESCs, DF-1 cells, and CEFs) were cultured in an incubator at $37^{\circ} \mathrm{C}$ under an atmosphere of $5 \%$ $\mathrm{CO}_{2}$ and $60-70 \%$ relative humidity.

Table 2 List of siRNA sequences targeting each transcription factor for knockdown analysis

\begin{tabular}{lll}
\hline $\begin{array}{l}\text { Target } \\
\text { gene }\end{array}$ & siRnA sequence $\left(\mathbf{5}^{\prime} \boldsymbol{\rightarrow} \mathbf{3}^{\prime}\right)$ & \\
\cline { 2 - 3 } Pense & Antisense \\
\hline POU5F3 & UGGCUCAAUGAGGCAGAGA & UCUCUGCCUCAUUGAGCCA \\
TP53 & AACCAAGACCCUGAUGAAG & CUUCAUCAGGGUCUUGGUU \\
CEBPA & GCGAGGAGGAGGAGGUGA & UUCACCUCCUCCUCCUCGC \\
CEBPB & GCGCAAGAGCCGCGACAAA & UUUGUCGCGGCUCUUGCGC \\
CEBPD & ACGAGAAGCUGCACAAGAA & UUCUUGUGCAGCUUCUCGU \\
CEBPG & AAAUUAAGCUCCUGACCAA & UUGGUCAGGAGCUUAAUUU \\
CEBPZ & GAGAAAAGCAAGAAGGAAA & UUUCCUUCUUGCUUUUCUC \\
\hline
\end{tabular}


Table 3 List of primer sequences used for quantitative real-time PCR

\begin{tabular}{lll}
\hline $\begin{array}{l}\text { Gene } \\
\text { symbol }\end{array}$ & Primer sequence $\left(\mathbf{5}^{\prime} \boldsymbol{\rightarrow} \mathbf{3} \mathbf{}\right)$ & \\
\cline { 2 - 3 } & Forward & Reverse \\
\hline CEBPA & CCCACCTGCAGTACCAGATC & TCTTTTGGATTTGCGCGG \\
CEBPB & CGCCCGCCTTAAATCCATG & GGGCTGAAGTCAATGGCTCT \\
CEBPD & ACTTCTACGACGCCAAGGTG & CTCTCGTCCTCGTACATGGC \\
CEBPG & CCCACAGCTAACGTGTCAGT & GGACGGGCTCTTCTTTGACA \\
CEBPZ & CGCTGTTCACAGTCTCCACT & GGACGCTGTGAGAAAGACCA \\
SOX2 & AAACCGAGCTGAAACCTCCC & TGTGCATCTTCGGGTTCTCC \\
SOX3 & CGGCTCAGCAGACTCGATAC & TCGCCGTGGCTTAAGAACTT \\
POU5F3 & TGAAGGGAACGCTGGAGAGC & ATGTCACTGGGATGGGCAGAC \\
TP53 & CCGTGGCCGTCTATAAGAAA & ACAGCACCGTGGTACAGTCA \\
NANOG & AGTGGCAGAGTCTGGGGTAT & ACTACTACTGGCCCTCTCCG \\
GAPDH & GGTGGTGCTAAGCGTGTAT & ACCTCTGTCATCTCTCCACA \\
\hline
\end{tabular}

\section{Prediction of putative TF-binding elements}

TF-binding sites were predicted by MatInspector, a Genomatix program (http://www.genomatix.de/) using TRANSFAC matrices (vertebrate matrix; core similarity 1.0 and matrix similarity 0.8), and PROMO 3.0, which uses TRANSFAC version 8.3 (http://alggen.lsi.upc.es/ cgi-bin/promo_v3/promo/promoinit.cgi?dirDB=TF_8.3).
Small interfering RNA (siRNA)-mediated knockdown of predicted TFs

siRNAs targeting predicted TFs were designed using siRNA Target Finder (http://www.ambion.com) (Table 2). Commercially available control siRNA (sense: 5' -CCU ACG CCA CCA AUU UCG U-3') was purchased from Bioneer Corporation (Daejeon, Korea). To validate the knockdown efficiency of predicted TFs, PGCs or ESCs were transfected with $50 \mathrm{pmol}$ of siRNAs targeting CCAAT/enhancer-binding protein $(C E B P)$ genes, including $C E B P A, C E B P B$, $C E B P D, C E B P G$, and $C E B P Z$, and TP53 using Lipofectamine 2000 (Invitrogen). After siRNA transfection for $24 \mathrm{~h}$, the knockdown efficiencies of the predicted TFs and the effects on $c N A N O G$ gene transcription were measured by quantitative reverse-transcription PCR (RT-qPCR).

\section{Analysis of gene expression by RT-qPCR}

Total RNA was extracted from test samples using TRIzol reagent (Molecular Research Center, USA) in accordance with the manufacturer's protocol and reverse-transcribed using the Superscript III First-Strand Synthesis System (Invitrogen). The PCR mixture contained $2 \mu \mathrm{L}$ of PCR buffer, $1 \mu \mathrm{L}$ of $20 \times$ EvaGreen qPCR dye (Biotium, Hayward, CA, USA), $0.4 \mu \mathrm{L}$ of $10 \mathrm{mmol} / \mathrm{L}$ dNTP mixture, and 10 pmol each of gene-specific forward and reverse primers (Table 3). RT-qPCR was performed in triplicate. Relative

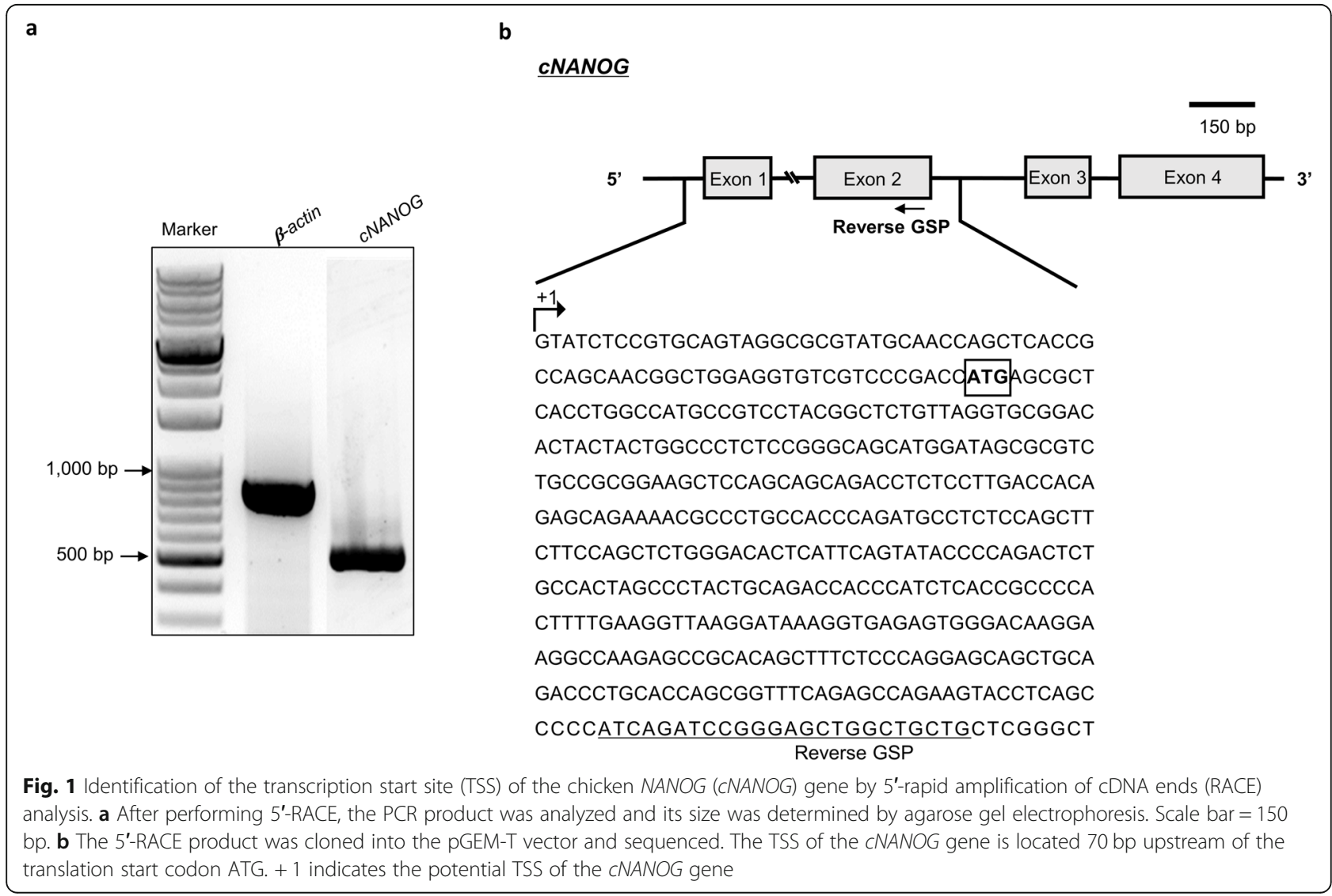




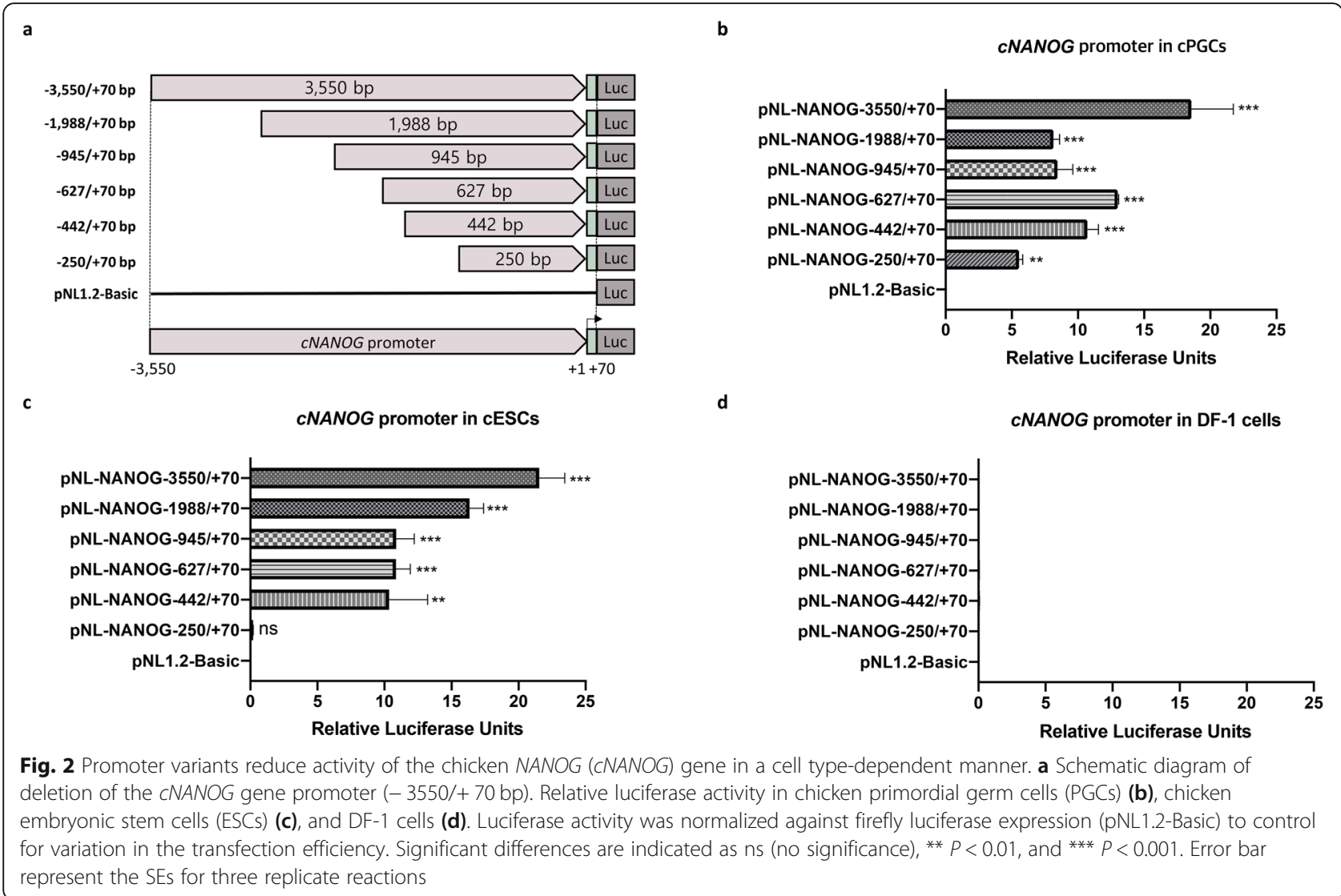

target gene expression was quantified after normalization against chicken glyceraldehyde 3-phosphate dehydrogenase (GAPDH) expression as an endogenous control.

\section{Statistical analysis}

Statistical analysis was performed using GraphPad Prism (GraphPad Software, La Jolla, CA, USA). Significant differences between groups were determined by a one-way analysis of variance with Bonferroni's multiple comparison test and the unpaired t-test. A value of $P<0.05$ indicated statistical significance.

\section{Results}

\section{Identification of the TSS of the CNANOG gene}

To better understand transcriptional regulation of the cNANOG gene, we first determined the TSS of this gene by $5^{\prime}$-RACE PCR analysis. A $470 \mathrm{bp}$ PCR product was obtained using a reverse GSP that targeted exon 2 of the cNANOG gene (Fig. 1a and b). Sequencing analysis identified the TSS of the $c N A N O G$ gene located $70 \mathrm{bp}$ upstream of the ATG start codon (Fig. 1b).

\section{Characterization of the cNANOG core promoter in PGCs and ESCs}

To investigate the proximal region of the core promoter of the $c N A N O G$ gene, we generated a series of $5^{\prime}$ deletion luciferase reporter constructs of the 6- region, which were randomly designed based on the $-3550 /+70 \mathrm{bp}$ sequence (Fig. 2a). Luciferase activity derived from differently sized fragments of the $c N A N O G$ promoter was examined in PGCs, ESCs, and DF-1 cells transfected with the constructs for $24 \mathrm{~h}$ using Lipofectamine 2000. Luciferase activity was 4-fold higher in PGCs transfected with the $-3550 /+70 \mathrm{bp}$ fragment than in PGCs transfected with the $-250 /+70 \mathrm{bp}$ fragment (Fig. 2b). On the other hand, the $-250 /+70 \mathrm{bp}$ fragment did not exhibit luciferase activity in ESCs (Fig. $2 \mathrm{c}$ ). None of the $c N A N O G$ promoter fragments were active in DF-1 cells (Fig. 2d). These results suggest that transactivation level of the complete promoter (-3550/+ 70 bp sequence) was similar between PGCs and ESCs but cNANOG transcription was differentially regulated in PGCs and ESCs by the proximal enhancer.

\section{POU5F3 and SOX2 regulate constitutive expression of cNANOG in PGCs}

To further examine PGC-specific cNANOG promoter activity and binding to the proximal enhancer, we generated four constructs harboring fragments of the $-250 /+$ $70 \mathrm{bp}$ region of the $c N A N O G$ promoter via deletion of the 5 ' upstream region. Among the four constructs, the $210 /+70 \mathrm{bp},-170 /+70 \mathrm{bp}$, and $-130 /+70 \mathrm{bp}$ fragments still showed promoter activity in PGCs, while the $-69 /+70$ 


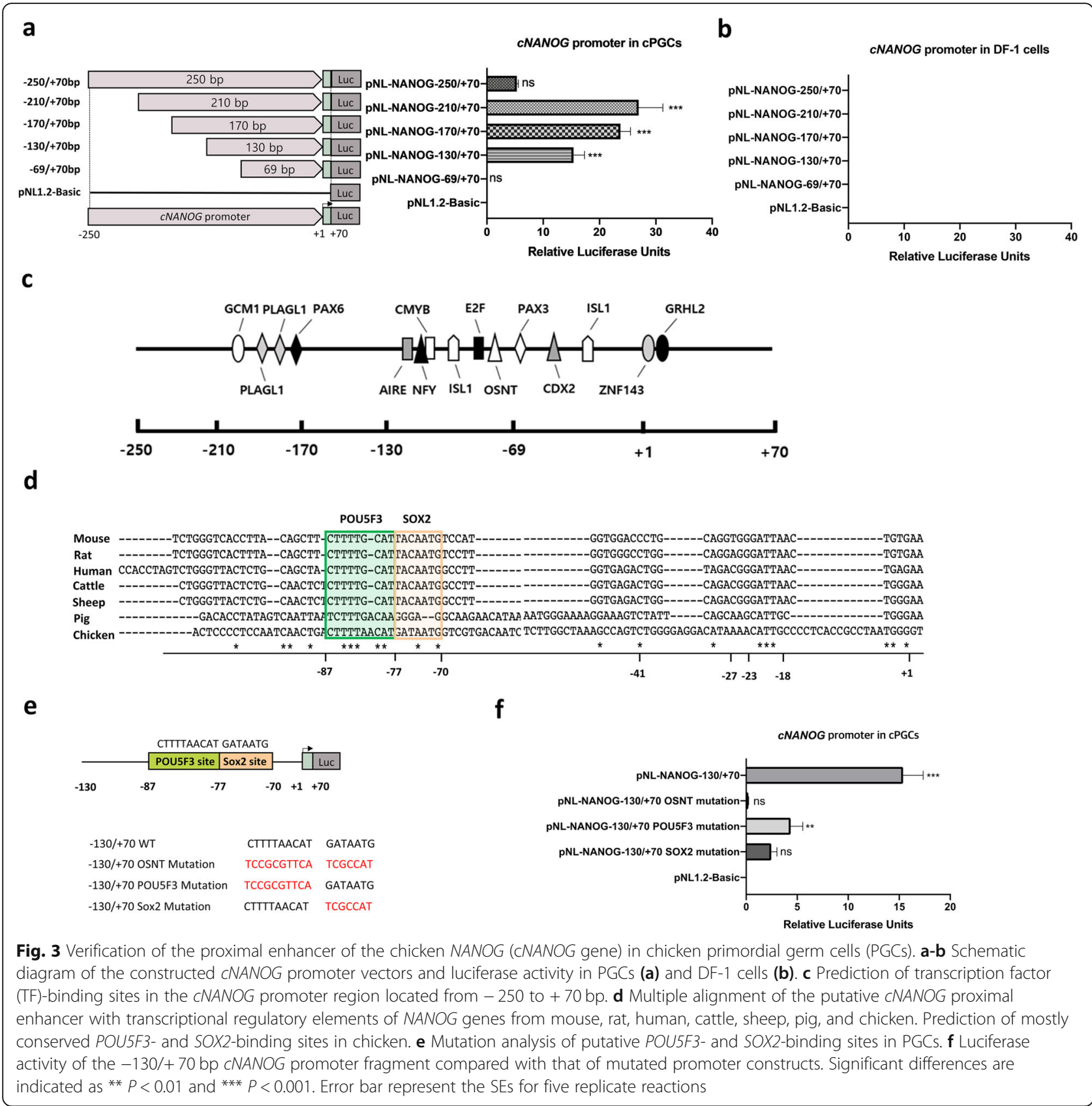

bp fragment did not (Fig. 3a). None of the $c$ NANOG promoter fragments were active in DF-1 cells (Fig. 3b). These results suggest that a positive transcriptional regulatory element is located between -130 and -69 bp in PGCs.

Based on the findings regarding $c N A N O G$ promoter activity described above, we predicted TFs with binding sites located between -130 and -69 bp of the $c N A N O G$ promoter using two software programs (PROMO and MatInspector). Several TF-binding sites, including AIRE-, $N F Y$-, CMYB-, ISL1-, E2F-, and OSNT (OCT4/ POU5F3, $S O X 2$, NANOG, and TCF3)-binding sites, were identified in this region (Fig. 3c). Sequence alignment of this
cNANOG promoter region from six vertebrate species showed that the POU5F3- and SOX2-binding regulatory elements are highly conserved in mammalian species (Fig. 3d). To determine the functional contributions of the POU5F3- and SOX2-binding sites to constitutive expression of $c N A N O G$, site-directed mutagenesis, which can disturb the recruitment of TFs, was performed (Fig. 3e). Mutation of the POU5F3/SOX2binding sites in the $200 \mathrm{bp}$ fragment $(-130 /+70 \mathrm{bp})$ significantly reduced relative luciferase activity in PGCs. Moreover, relative luciferase activity was reduced significantly more by mutation of the SOX2-binding site 
alone than by mutation of the POU5F3-binding site alone in PGCs (Fig. 3f). Taken together, these results suggest that POU $5 F 3$ and $S O X 2$ play a role in transcription of $c N A N O G$ by directly binding to the $5^{\prime}$ upstream promoter region in PGCs.

\section{TP53 suppresses CNANOG gene expression in PGCs}

Luciferase activity was at least 3-fold higher in PGCs transfected with the $-210 /+70 \mathrm{bp},-170 /+70 \mathrm{bp}$, and -
$130 /+70$ bp fragments than in PGCs transfected with the $-250 /+70 \mathrm{bp}$ fragment (Fig. 3a). These results suggest that a negative transcriptional regulatory element is located between -250 and $-210 \mathrm{bp}$. To investigate the suppression of $c N A N O G$ promoter activity, we predicted TFs that have binding sites within this region using two software programs (PROMO and MatInspector) (Fig. 4a). Among the predicted TFs, TP53 is a suppressor of NANOG transcription, while ZIC2/3 and CEBP are

\section{a}

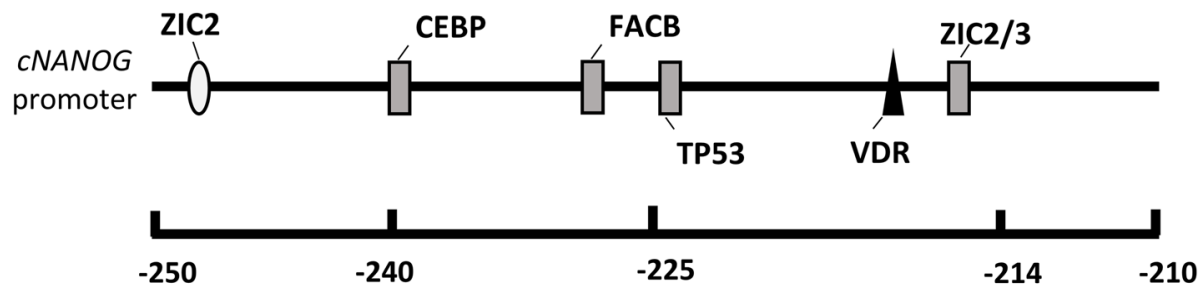

b

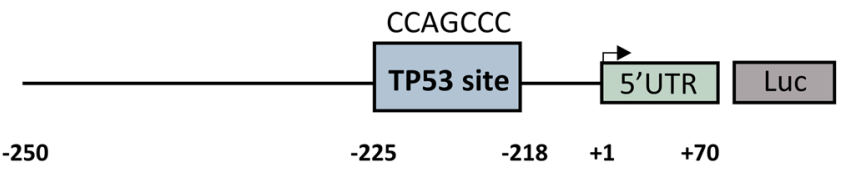

$-250 /+70$ WT CCAGCCC

-250/+70 TP53 Mutation TTTAAAA

C

cNANOG promoter in cPGCs

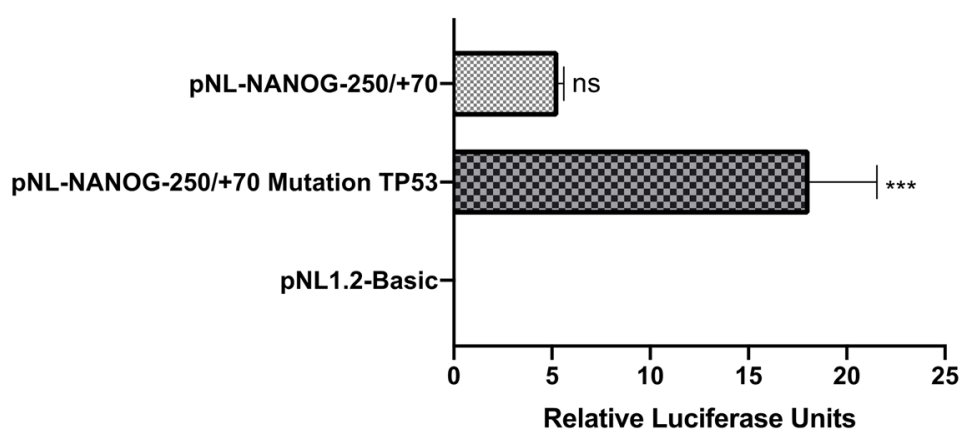

Fig. 4 Negative regulation of chicken NANOG (CNANOG) gene expression by TP53 in chicken primordial germ cells (PGCs). a Prediction of transcription factor (TF)-binding sites in the CNANOG promoter region from - 250 to $-210 \mathrm{bp}$. b Mutation analysis of putative TP53-binding sites in PGCs. c Luciferase activity of pNL-NANOG - 250/+ 70 and TP53-binding site-mutated (pNL-NANOG - 250/+ 70 TP53 mutation) vectors. pNL1.2Basic was used as a control. Significant differences are indicated as ns (no significance) and ${ }^{* * *} P<0.001$. Error bar represent the SEs for five replicate reactions 


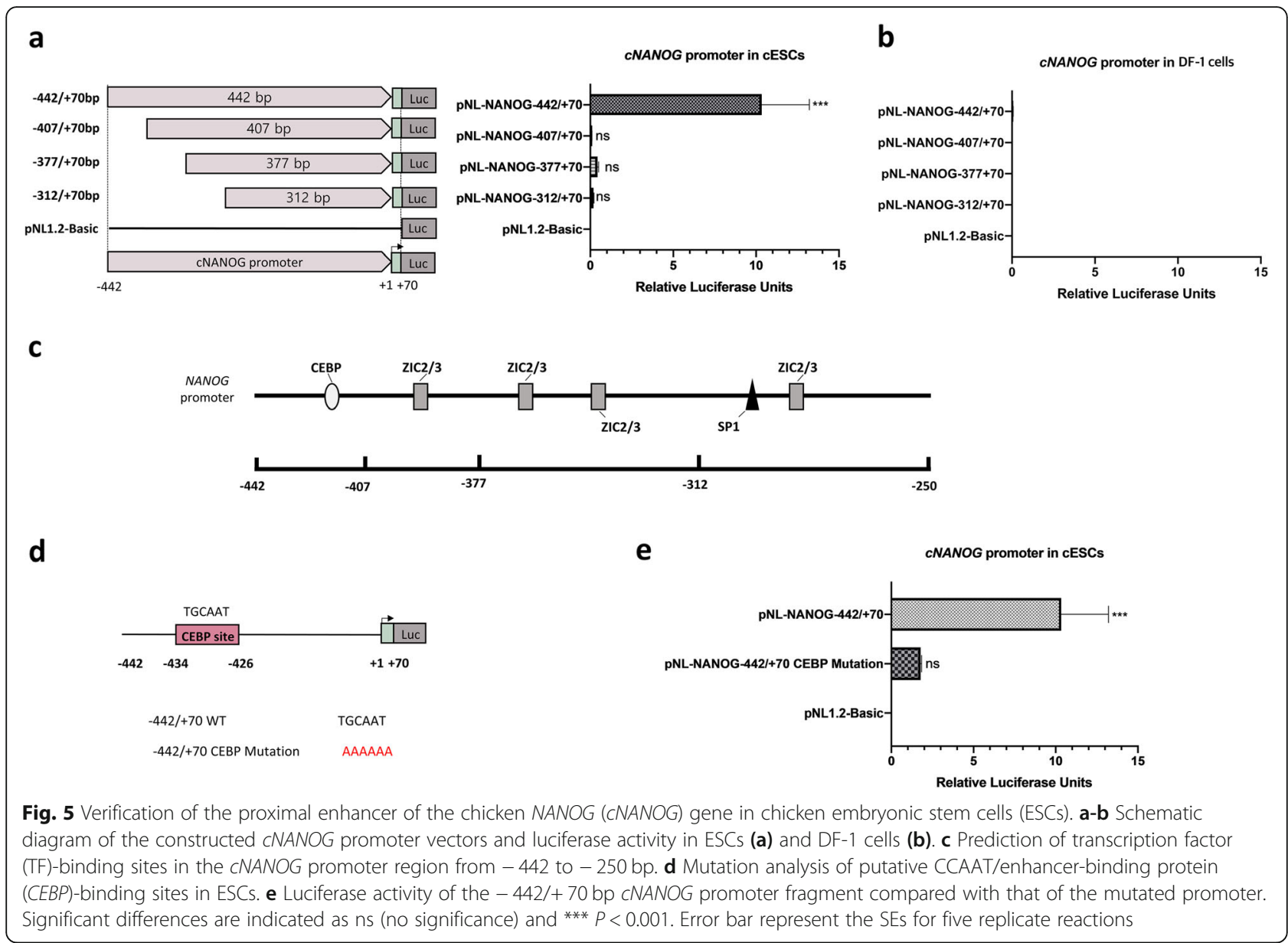

positive regulators of NANOG transcription [28, 40, 41]. We further examined whether TP53 affects cNANOG promoter activity in PGCs by performing site-directed mutagenesis and comparing the mutant with the wildtype $-250 /+70 \mathrm{bp}$ fragment (Fig. 4b). Deletion of the TP53-binding site in the $c N A N O G$ promoter region significantly increased luciferase activity in PGCs (Fig. 4c). These results demonstrate that TP53 suppresses $c N A$ NOG transcription in PGCs.

\section{CEBP transactivates the CNANOG promoter in ESCs}

To further investigate the potential transcriptional regulatory elements in ESCs, we generated four constructs harboring fragments of the $-442 /+70 \mathrm{bp}$ region of the cNANOG promoter via deletion of the $5^{\prime}$ upstream region. Among the four constructs, the $-407 /+70 \mathrm{bp}$, $377 /+70 \mathrm{bp}$, and $-312 /+70 \mathrm{bp}$ fragments exhibited significantly reduced $c N A N O G$ promoter activity in ESCs (Fig. 5a). None of the $c N A N O G$ promoter fragments were active in DF-1 cells (Fig. 5b). These results suggest that a positive transcriptional regulatory element is located between - 442 and -407 bp in ESCs.
We analyzed the $-442 /+70 \mathrm{bp}$ fragment using two software programs (PROMO and MatInspector) to identify important TF-binding sites that maintain the basal activity of the $c N A N O G$ gene in ESCs. Only a CEBPbinding site was identified between -442 and $-407 \mathrm{bp}$ (Fig. 5c). To examine the effect of the CEBP-binding site on promoter activity, we constructed vectors containing mutations of this site in the $-422 /+70 \mathrm{bp}$ fragment (Fig. $5 d)$. Mutation of the CEBP-binding site in the $-442 /+$ $70 \mathrm{bp}$ region dramatically reduced relative luciferase activity in ESCs compared with the wild-type construct of the same region (Fig. 5e). Taken together, these results suggest that $C E B P$ positively regulates transcription of $c N A N O G$ by directly binding to the $5^{\prime}$ upstream promoter region in ESCs.

\section{Effects of predicted TFs on cNANOG gene transcription}

To confirm that the predicted TFs are expressed in PGCs and ESCs, we conducted RT-qPCR using RNA prepared from PGCs, ESCs, DF-1 cells, and CEFs. Expression of chicken $C E B P$ genes (CEBPA, CEBPB, $C E B P D, C E B P G$, and $C E B P Z$ ) was significantly higher in ESCs than in other cells. By contrast, expression of 
POU5F3 and SOX2/3 was significantly higher in PGCs and ESCs than in DF-1 cells and CEFs. Expression of POU5F3 and SOX3 did not differ between PGCs and ESCs, while SOX2 was significantly upregulated in PGCs. Additionally, expression of TP53 was significantly higher in PGCs than in other cells (Fig. 6).

We further examined whether these TFs affect the transcription of $c N A N O G$ in PGCs and ESCs using a siRNA-mediated knockdown assay. Knockdown of TP53 significantly increased $c N A N O G$ expression in PGCs, indicating that TP53 decreases $c N A N O G$ transcription (Fig. 7a). Knockdown of CEBPA, CEBPB, CEBPD, $C E B P G$, and $C E B P Z$ significantly decreased $c N A N O G$ gene expression in ESCs (Fig. $7 \mathrm{~b}-\mathrm{f}$ ). We also examined the luciferase activities driven by cNANOG promoter containing wild type binding sites after the knockdown of predicted TFs in PGCs and ESCs (Fig. 8). Knockdown of POU5F3 and SOX2 significantly reduced the activity of the cNANOG promoter fragment $(-130 /+70 \mathrm{bp})$ containing wild type binding sites, whereas, knockdown of TP53 is significantly increased the activity of the cNANOG promoter $-250 /+70$ bp fragment in PGCs (Fig. 8a and b). Knockdown of $C E B P A, C E B P B, C E B P D, C E B P G$, and $C E B P Z$ in ESCs dramatically reduced the activity of the cNANOG promoter $-442 /+70$ bp fragment containing wild type $C E B P$ binding site (Fig. 8c). These results indicate that these TFs control transcription of $c N A N O G$ by directly interacting with its promoter in a cell typespecific manner.

\section{Discussion}

The homeodomain TF NANOG is important to maintain pluripotency in mammalian pluripotent cells during embryonic development [17]. Therefore, many studies have been conducted to determine how NANOG expression is regulated by core factors in mammalian stem cells [20, $22,23]$. In addition, its expression is required for the formation of germ cells [30] and maintained in proliferating PGCs during the migration [42]. It has been recently reported that regulatory elements of NANOG transcription in PGCs are different from the ES cells in mice but key regulatory factors have not yet been identified [43]. In chicken, NANOG was also important for maintaining the pluripotency in PGCs and ESCs [31, 35, 38, 44]. However, the molecular mechanisms that regulate transcription of the NANOG gene in chicken PGCs and ESCs remain unclear. In this regard, we characterized the structure of $c N A N O G$ and analyzed its promoter activity in chicken PGCs and ESCs.

We successfully transcribed $c N A N O G$ under the control of the proximal regulatory region located within 130 bp upstream of the TSS in PGCs. Furthermore, we

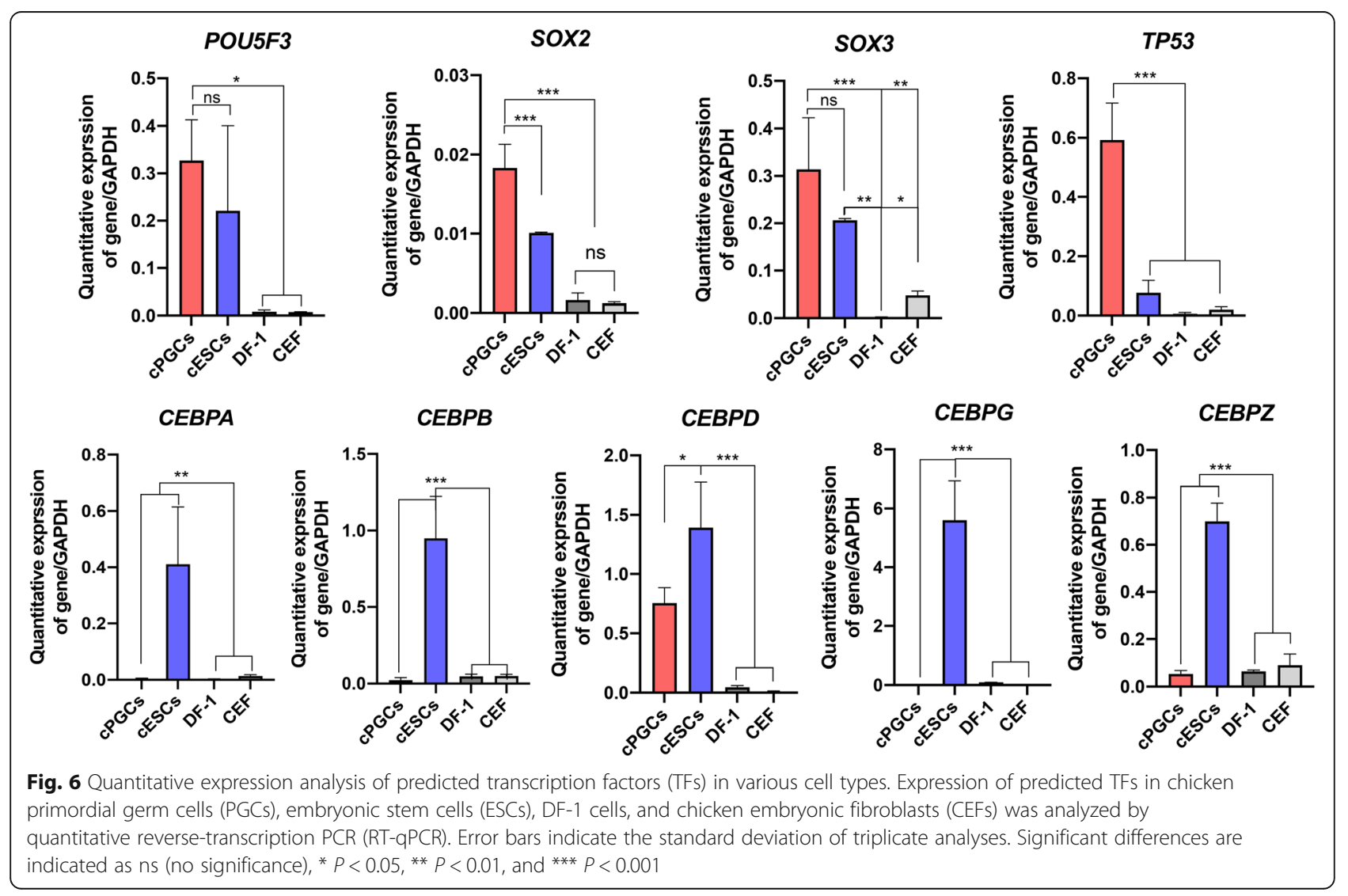




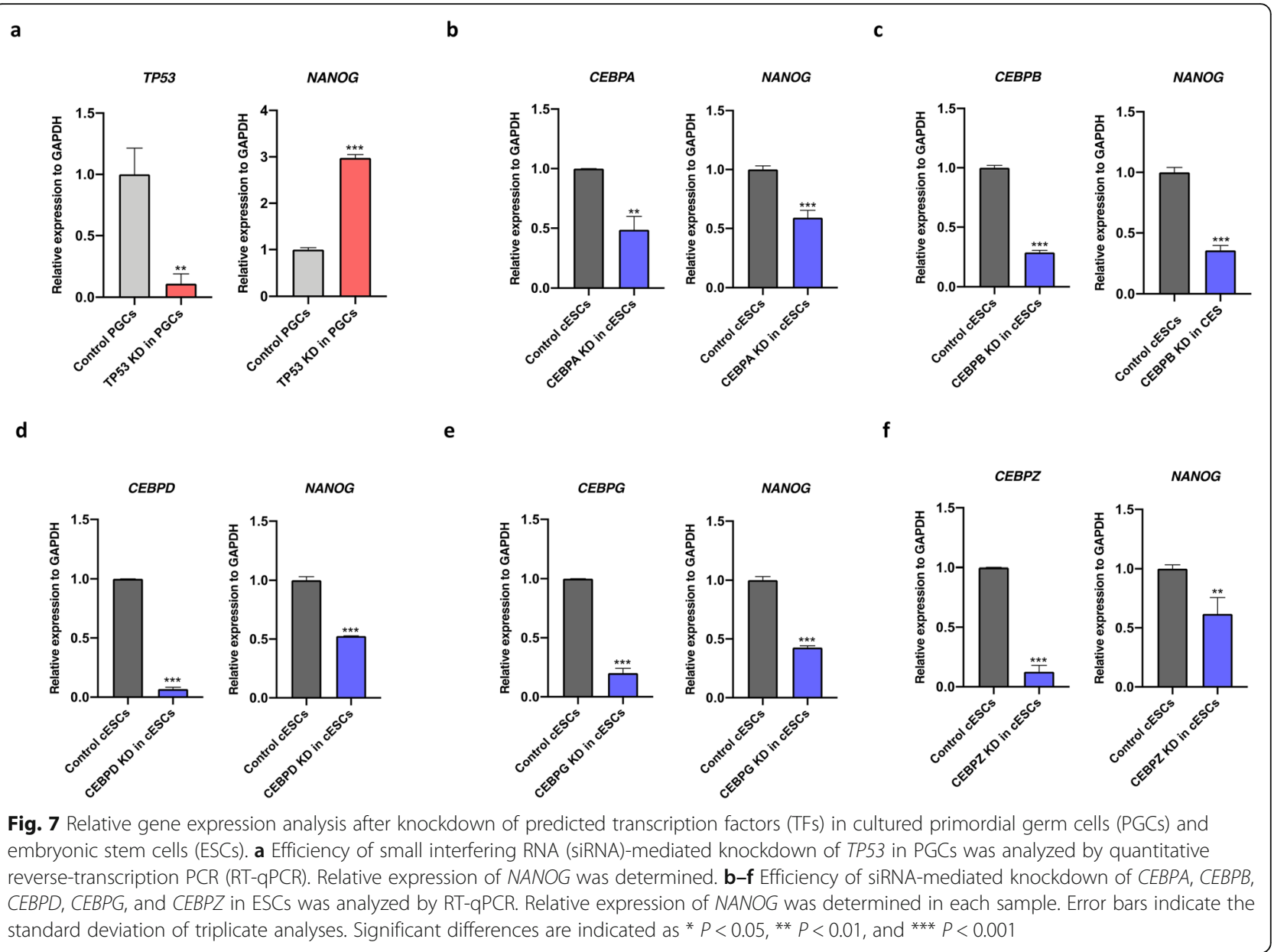

identified the regulatory region of $c N A N O G$ located within $442 \mathrm{bp}$ upstream of the TSS in ESCs. Moreover, we showed that TP53 suppresses $c N A N O G$ transcription in PGCs. These results suggest that the $c N A N O G$ promoter functions in a cell type-specific manner. Similarly, Yeom et al. reported that the mouse Oct4 gene contains two separate regulatory elements [45]. The distal regulatory element is specifically active in mouse ESCs and EGCs, while the proximal enhancer is active in the epiblast. Thus, transcription of the mouse Oct4 gene is regulated in a stage-specific manner. Our findings indicate which elements are critical for gene expression in PGCs. This is the first report of a transcriptional regulatory factors of NANOG that is differentially active in a cell typespecific manner in chicken.

Many researchers have studied mammalian ESCs to determine which core factors regulate the NANOG gene. Most of the positive regulation of NANOG transcription has been discovered in the proximal region, which encompasses OCT3/4 and SOX2 in mouse ESCs. This region is strongly conserved in various mammalian species $[20,23]$. Mutation of Octamer- and Sox-binding sites dramatically reduces transcription of NANOG.
Therefore, OCT3/4 and SOX2 play an important role in regulation of the NANOG gene promoter in mammalian ESCs [23]. Also, these TFs such as POU5F3, SOX2/3, $K L F 2$, and SALL4 are highly expressed in chicken ES cells and PGCs [46]. According to the comparison of genomic sequence elements, core pluripotency factors of the mouse are not conserved with chicken [47]. In the present study, mutation of POU5F3- and SOX2-binding sites in the proximal region significantly reduced $\mathrm{cNA}$ NOG promoter activity in PGCs. Although the DNA sequences of POU5F3 and $S O X 2$, which are recognized by mouse core pluripotency factors, are not well conserved in chicken, POU5F3 and SOX2 are key regulators of cNANOG transcription. Further investigation by the electrophoretic mobility shift assay and chromatin immunoprecipitation sequencing is required to determine the core TFs in chicken PGCs.

Programmed death of PGCs is essential to remove abnormal, misplaced, and excess cells during PGC development and this is important to establish the next generation. In Drosophila melanogaster, TP53 is reportedly involved in elimination of excess PGCs during PGC development [48] and, mouse PGCs are regulated by p53 


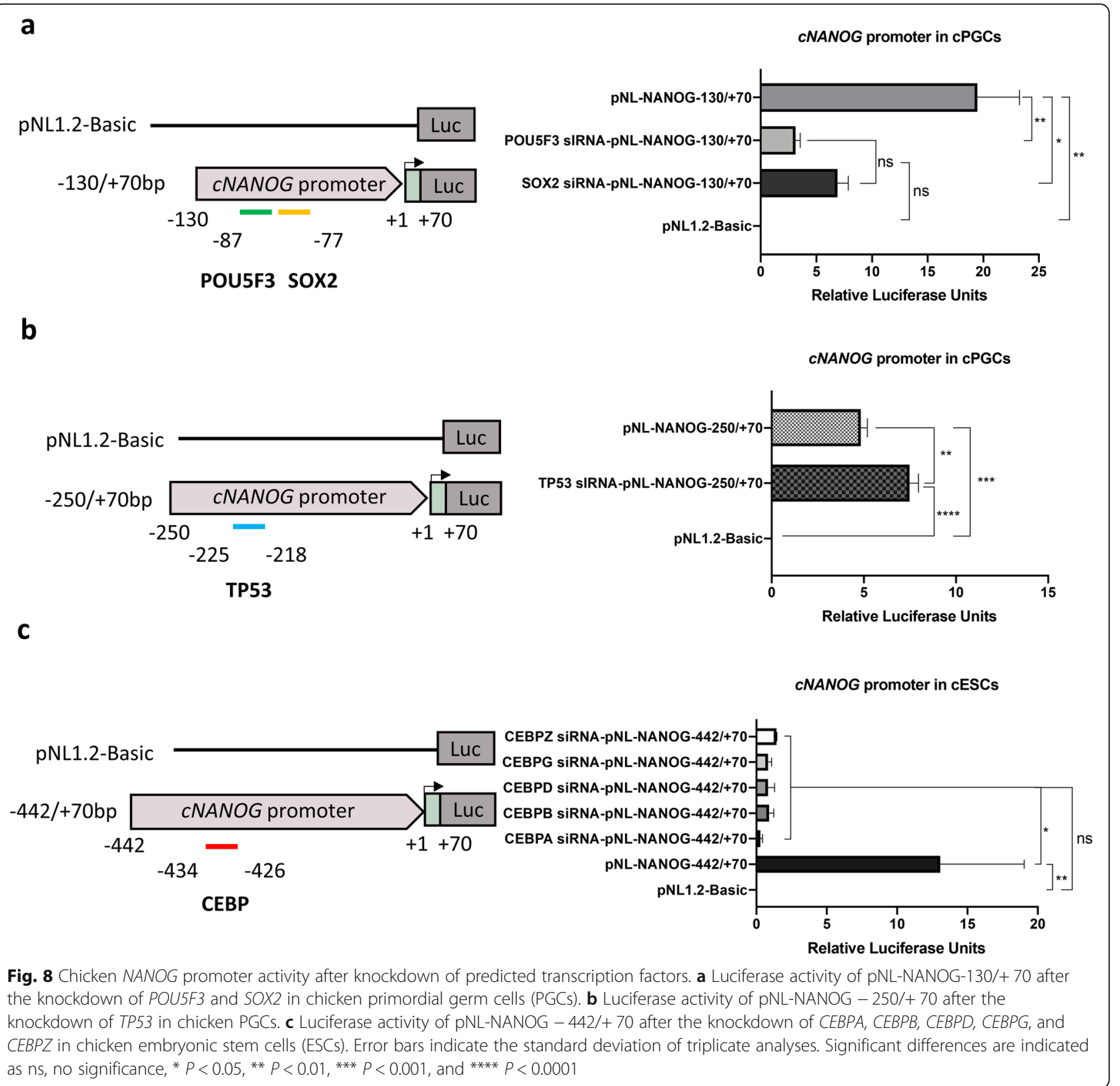

to process the PGCs apoptosis [49]. In addition, TP53 binds to the NANOG promoter and suppresses NANOG expression for maintenance of genome stability in ESCs [28]. Interestingly, our results showed that the TP53binding site negatively controlled NANOG transcription in chicken PGCs. Therefore, we propose that TP53 plays important roles in the regulation of NANOG transcription to maintain genome stability in PGCs.

$C E B P B$ interacts with $p 300$ to modulate histone acetylation [50], and p300 is a co-activator that binds to NANOG for maintenance of pluripotency in ESCs [51]. In our study, $C E B P A, C E B P B, C E B P D, C E B P G$, and $C E B P Z$ were significantly upregulated in chicken ESCs.
In addition, knockdown of these TFs dramatically decreased transcription of $c N A N O G$ in chicken ESCs. These results suggest that $C E B P$ in chicken ESCs participate in regulation of $c N A N O G$ transcription by directly interacting with putative binding sites in the $c N A N O G$ promoter.

As described above, transcription regulation of $\mathrm{cNA}$ NOG is conserved in mammals, although DNA sequences of regulation factors differ between chicken and mammals. Typically, mammalian PGCs can be induced by cell signaling [52]. Interestingly, mouse Nanog is key regulator of PGCs-like cells independent of BMP4 and Wnt signals by activating the expression of germ cell- 


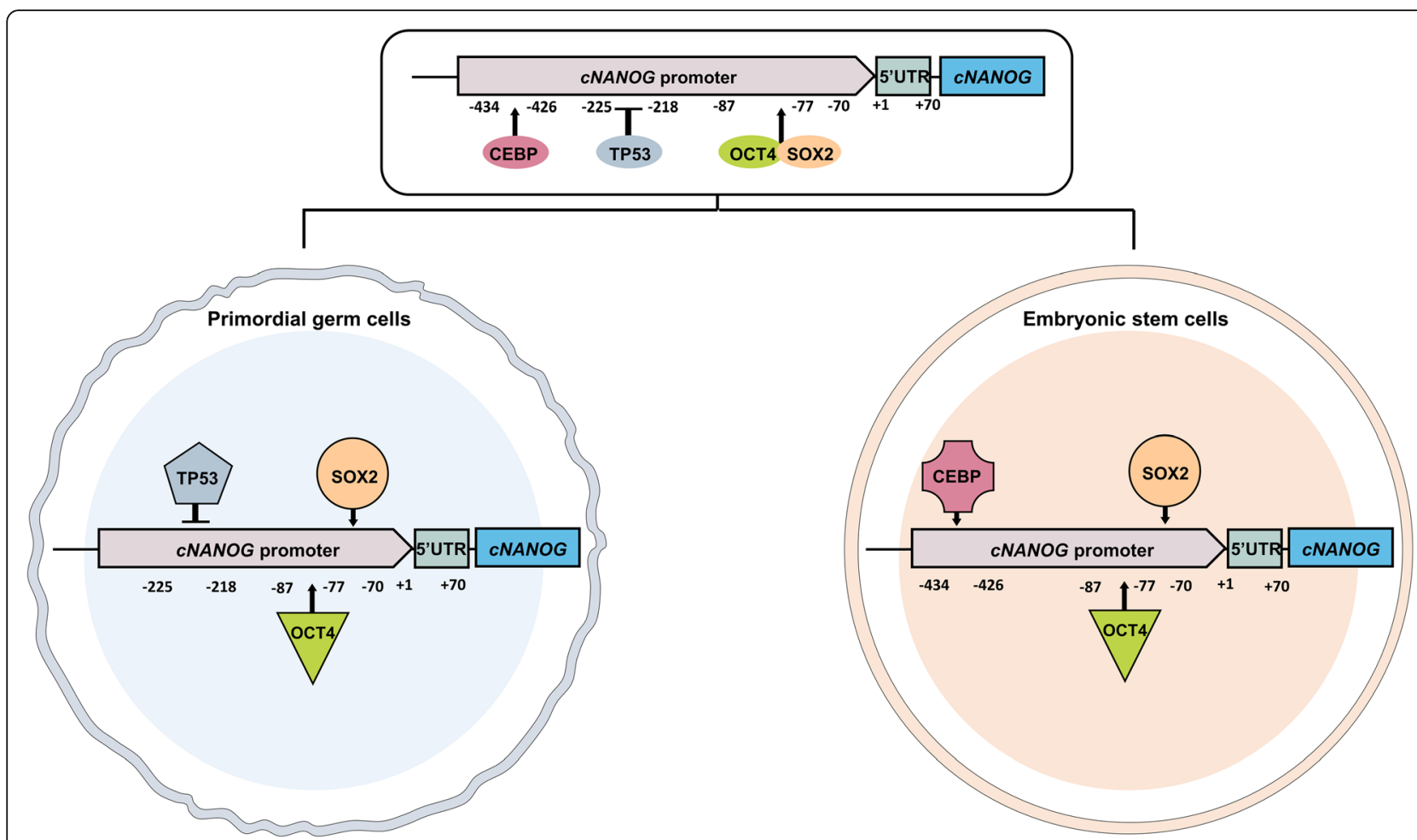

Fig. 9 A model illustrating regulation of chicken NANOG (CNANOG) gene transcription in chicken primordial germ cells (PGCs) and embryonic stem cells (ESCS). CNANOG gene expression requires transcriptional trans-regulatory elements that are positively controlled by POU5F3 and SOX2 and negatively controlled by TP53 in PGCs. On the other hand, CCAAT/enhancer-binding protein (CEBP) positively regulates CNANOG gene expression in ESCS

specific TFs [33]. On the other hand, chicken germ cells may be specified by maternally inherited factors like $V A S A$ and DAZL in germ plasm [53, 54]. Recently, the epigenetic regulation of NANOG in chicken PGCs has been investigated by our group to understand the molecular mechanisms involved in the specification of germ cells [34]. However, the regulation of cNANOG in chicken germ cell specification is still unclear. In this study, we shown that chicken NANOG has differential regulatory roles in PGCs and ESCs, even though cNANOG promoter region sharing the common transcription factor binding sites. These finding provided insights into germ cell and stem cell-specific transcriptional regulatory mechanisms.

\section{Conclusion}

This study demonstrated that the proximal regulatory region of the $c N A N O G$ gene differs between PGCs and ESCs. We showed that the $c N A N O G$ gene is positively regulated by $P O U 5 F 3$ and $S O X 2$ and negatively regulated by TP53 in PGCs, while it is positively regulated by $C E B P$ in ESCs. Collectively, these findings aid understanding of transcriptional regulation of the $c N A N O G$ gene in PGCs and ESCs (Fig. 9).

\section{Abbreviations}

TF: Transcription factor; ESCs: Embryonic stem cells; PGCs: Primordial germ cells; CNANOG: Chicken NANOG; CEBP: CCAAT/enhancer-binding protein; EGCs: Embryonic germ cells; TSS: Transcription start site; HH5: Hamburger and Hamilton stage 5; WL: White Leghorn; 5'-RACE: 5' Rapid amplification of cDNA ends; GSPs: Gene-specific primers; Fluc: Firefly luciferase;

Nluc: NanoLuc luciferase; AU: Arbitrary units; CEF: Chicken embryonic

fibroblasts; GAPDH: Glyceraldehyde 3-phosphate dehydrogenase

\section{Acknowledgments}

Not applicable.

\section{Authors' contributions}

HJC participated in the design of the study, carried out the experiments, statistical analysis and wrote the first draft of the manuscript. SDJ, JHK, and DR carried out and analyzed the experiments. DR, BP, JYH participated in writing the final versions of the manuscript. JYH participated in the design of the study and overall coordination. All authors have read and approved the final manuscript.

\section{Funding}

This work was supported by a National Research Foundation of Korea (NRF) grant funded by the Korea government (MSIP) [2015R1A3A2033826] and [2018R1D1A1B07049376].

\section{Availability of data and materials}

The datasets during and/or analyzed during the current study available from the corresponding authors on reasonable request.

\section{Ethics approval and consent to participate}

The care and experimental use of chickens were approved by the Institute of Laboratory Animal Resources, Seoul National University. 


\section{Consent for publication}

Not applicable.

\section{Competing interests}

The authors declare that they have no competing interests.

\section{Author details}

'Department of Agricultural Biotechnology and Research Institute of Agriculture and Life Sciences, Seoul National University, Seoul 08826, South Korea. ${ }^{2}$ Univ Lyon, Universite' Lyon 1, INSERM, INRAE, Stem Cell and Brain Research Institute, U1208, USC1361, 69500 Bron, France. ${ }^{3}$ Institute for Biomedical Sciences, Shinshu University, Minamiminowa, Nagano 399-4598, Japan

Received: 21 September 2020 Accepted: 26 January 2021

\section{Published online: 04 March 2021}

\section{References}

1. Segal E, Widom J. From DNA sequence to transcriptional behaviour: a quantitative approach. Nat Rev Genet. 2009;10(7):443-56.

2. Sonawane AR, Platig J, Fagny M, Chen CY, Paulson JN, Lopes-Ramos CM, et al. Understanding tissue-specific gene regulation. Cell Rep. 2017;21(4):1077-88.

3. Meckbach C, Tacke R, Hua X, Waack S, Wingender E, Gultas M. PC-TraFF: identification of potentially collaborating transcription factors using pointwise mutual information. BMC Bioinformatics. 2015;16:400.

4. Merienne N, Meunier C, Schneider A, Seguin J, Nair SS, Rocher AB, et al. Cell-type-specific gene expression profiling in adult mouse brain reveals normal and disease-state signatures. Cell Rep. 2019;26(9):2477-93 e9.

5. Gurdon JB, Javed K, Vodnala M, Garrett N. Long-term association of a transcription factor with its chromatin binding site can stabilize gene expression and cell fate commitment. Proc Natl Acad Sci U S A. 2020; 117(26):15075-84.

6. Strome S, Updike D. Specifying and protecting germ cell fate. Nat Rev Mol Cell Biol. 2015;16(7):406-16

7. Eddy EM, O'Brien DA. Gene expression during mammalian meiosis. Curr Top Dev Biol. 1998;37:141-200.

8. Song JL, Wessel GM. How to make an egg: transcriptional regulation in oocytes. Differentiation. 2005;73(1):1-17.

9. Grimes SR. Testis-specific transcriptional control. Gene. 2004;343(1):11-22

10. White-Cooper $H$, Davidson I. Unique aspects of transcription regulation in male germ cells. Cold Spring Harb Perspect Biol. 2011;3(7):a002626.

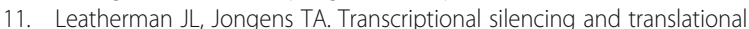
control: key features of early germline development. Bioessays. 2003;25(4): 326-35.

12. DeJong J. Basic mechanisms for the control of germ cell gene expression. Gene. 2006:366(1):39-50.

13. Hiller M, Chen X, Pringle MJ, Suchorolski M, Sancak Y, Viswanathan S, et al. Testis-specific TAF homologs collaborate to control a tissue-specific transcription program. Development. 2004;131(21):5297-308.

14. Wang J, Rao S, Chu J, Shen X, Levasseur DN, Theunissen TW, et al. A protein interaction network for pluripotency of embryonic stem cells. Nature. 2006; 444(7117):364-8

15. Boyer LA, Lee TI, Cole MF, Johnstone SE, Levine SS, Zucker JP, et al. Core transcriptional regulatory circuitry in human embryonic stem cells. Cell. 2005:122(6):947-56

16. Kim J, Chu J, Shen X, Wang J, Orkin SH. An extended transcriptional network for pluripotency of embryonic stem cells. Cell. 2008;132(6):1049-61.

17. Chambers I, Colby D, Robertson M, Nichols J, Lee S, Tweedie S, et al. Functional expression cloning of Nanog, a pluripotency sustaining factor in embryonic stem cells. Cell. 2003;113(5):643-55.

18. Mitsui K, Tokuzawa Y, Itoh H, Segawa K, Murakami M, Takahashi K, et al. The homeoprotein Nanog is required for maintenance of pluripotency in mouse epiblast and ES cells. Cell. 2003;113(5):631-42.

19. Wang SH, Tsai MS, Chiang MF, Li H. A novel NK-type homeobox gene, ENK (early embryo specific NK), preferentially expressed in embryonic stem cells. Gene Expr Patterns. 2003:3(1):99-103.

20. Rodda DJ, Chew JL, Lim LH, Loh YH, Wang B, Ng HH, et al. Transcriptional regulation of nanog by OCT4 and SOX2. J Biol Chem. 2005;280(26):24731-7.

21. Loh YH, Wu Q, Chew JL, Vega VB, Zhang W, Chen X, et al. The Oct4 and Nanog transcription network regulates pluripotency in mouse embryonic stem cells. Nat Genet. 2006;38(4):431-40.
22. Karwacki-Neisius V, Goke J, Osorno R, Halbritter F, Ng JH, Weisse AY, et al. Reduced Oct4 expression directs a robust pluripotent state with distinct signaling activity and increased enhancer occupancy by Oct4 and Nanog. Cell Stem Cell. 2013;12(5):531-45.

23. Kuroda T, Tada M, Kubota H, Kimura H, Hatano SY, Suemori H, et al. Octamer and sox elements are required for transcriptional cis regulation of Nanog gene expression. Mol Cell Biol. 2005;25(6):2475-85.

24. Chen $X$, Fang F, Liou YC, Ng HH. Zfp143 regulates Nanog through modulation of Oct4 binding. Stem Cells. 2008;26(11):2759-67.

25. Wu DY, Yao Z. Functional analysis of two Sp1/Sp3 binding sites in murine Nanog gene promoter. Cell Res. 2006;16(3):319-22.

26. Wu Q, Chen X, Zhang J, Loh YH, Low TY, Zhang W, et al. Sall4 interacts with Nanog and co-occupies Nanog genomic sites in embryonic stem cells. J Biol Chem. 2006;281(34):24090-4.

27. Liu W, Stein P, Cheng X, Yang W, Shao NY, Morrisey EE, et al. BRD4 regulates Nanog expression in mouse embryonic stem cells and preimplantation embryos. Cell Death Differ. 2014:21(12):1950-60.

28. Lin T, Chao C, Saito S, Mazur SJ, Murphy ME, Appella E, et al. p53 induces differentiation of mouse embryonic stem cells by suppressing Nanog expression. Nat Cell Biol. 2005;7(2):165-71.

29. Clark AT, Reijo Pera RA. Modeling human germ cell development with embryonic stem cells. Regen Med. 2006;1(1):85-93.

30. Chambers I, Silva J, Colby D, Nichols J, Nijmeijer B, Robertson M, et al. Nanog safeguards pluripotency and mediates germline development. Nature. 2007:450(7173):1230-4.

31. Choi HJ, Kim I, Lee HJ, Park YH, Suh JY, Han JY. Chicken NANOG selfassociates via a novel folding-upon-binding mechanism. FASEB J. 2018;32(5): $2563-73$

32. Yamaguchi S, Kurimoto K, Yabuta Y, Sasaki H, Nakatsuji N, Saitou M, et al. Conditional knockdown of Nanog induces apoptotic cell death in mouse migrating primordial germ cells. Development. 2009;136(23):4011-20.

33. Murakami K, Gunesdogan U, Zylicz JJ, Tang WWC, Sengupta R, Kobayashi T, et al. NANOG alone induces germ cells in primed epiblast in vitro by activation of enhancers. Nature. 2016:529(7586):403-7.

34. Jung HG, Hwang YS, Park YH, Cho HY, Rengaraj D, Han JY. Role of epigenetic regulation by the REST/CoREST/HDAC corepressor complex of moderate NANOG expression in chicken primordial germ cells. Stem Cells Dev. 2018:27(17):1215-25.

35. Lavial F, Acloque H, Bertocchini F, Macleod DJ, Boast S, Bachelard E, et al. The Oct4 homologue PouV and Nanog regulate pluripotency in chicken embryonic stem cells. Development. 2007;134(19):3549-63.

36. Theunissen TW, Costa Y, Radzisheuskaya A, van Oosten AL, Lavial F, Pain B, et al. Reprogramming capacity of Nanog is functionally conserved in vertebrates and resides in a unique homeodomain. Development. 2011; 138(22):4853-65.

37. Dixon JE, Allegrucci C, Redwood C, Kump K, Bian Y, Chatfield J, et al. Axolotl Nanog activity in mouse embryonic stem cells demonstrates that ground state pluripotency is conserved from urodele amphibians to mammals. Development. 2010;137(18):2973-80.

38. Han JY, Lee HG, Park YH, Hwang YS, Kim SK, Rengaraj D, et al. Acquisition of pluripotency in the chick embryo occurs during intrauterine embryonic development via a unique transcriptional network. J Anim Sci Biotechnol. 2018;9:31.

39. Pain B, Clark ME, Shen M, Nakazawa H, Sakurai M, Samarut J, et al. Long-term in vitro culture and characterisation of avian embryonic stem cells with multiple morphogenetic potentialities. Development. 1996;122(8):2339-48.

40. Lim LS, Hong FH, Kunarso G, Stanton LW. The pluripotency regulator Zic3 is a direct activator of the Nanog promoter in ESCs. Stem Cells. 2010;28(11):1961-9.

41. Patra SK, Vemulawada C, Soren MM, Sundaray JK, Panda MK, Barman HK. Molecular characterization and expression patterns of Nanog gene validating its involvement in the embryonic development and maintenance of spermatogonial stem cells of farmed carp, Labeo rohita. J Anim Sci Biotechnol. 2018;9:45.

42. Yamaguchi $\mathrm{S}$, Kimura H, Tada M, Nakatsuji N, Tada T. Nanog expression in mouse germ cell development. Gene Expr Patterns. 2005;5(5):639-46.

43. Terada M, Kawamata M, Kimura R, Sekiya S, Nagamatsu G, Hayashi K, et al. Generation of Nanog reporter mice that distinguish pluripotent stem cells from unipotent primordial germ cells. Genesis. 2019.57(1112):e23334. 
44. Canon S, Herranz C, Manzanares M. Germ cell restricted expression of chick Nanog. Dev Dyn. 2006;235(10):2889-94.

45. Yeom Yl, Fuhrmann G, Ovitt CE, Brehm A, Ohbo K, Gross M, et al. Germline regulatory element of Oct-4 specific for the totipotent cycle of embryonal cells. Development. 1996;122(3):881-94.

46. Jean C, Oliveira NM, Intarapat S, Fuet A, Mazoyer C, De Almeida I, et al. Transcriptome analysis of chicken ES, blastodermal and germ cells reveals that chick ES cells are equivalent to mouse ES cells rather than EpiSC. Stem Cell Res. 2015;14(1):54-67.

47. Fernandez-Tresguerres B, Canon S, Rayon T, Pernaute B, Crespo M, Torroja C, et al. Evolution of the mammalian embryonic pluripotency gene regulatory network. P Natl Acad Sci USA. 2010;107(46):19955-60.

48. Yamada Y, Davis KD, Coffman CR. Programmed cell death of primordial germ cells in Drosophila is regulated by $\mathrm{p} 53$ and the outsiders monocarboxylate transporter. Development. 2008;135(2):207-16.

49. De Felici M, Klinger FG. Programmed cell death in mouse primordial germ cells. Int J Dev Biol. 2015:59(1-3):41-9.

50. Cesena TI, Cardinaux JR, Kwok R, Schwartz J. CCAAT/enhancer-binding protein (C/EBP) beta is acetylated at multiple lysines: acetylation of C/ EBPbeta at lysine 39 modulates its ability to activate transcription. J Biol Chem. 2007;282(2):956-67.

51. Goke J, Jung M, Behrens S, Chavez L, O'Keeffe S, Timmermann B, et al. Combinatorial binding in human and mouse embryonic stem cells identifies conserved enhancers active in early embryonic development. PLoS Comput Biol. 2011;7(12):e1002304.

52. Extavour CG, Akam M. Mechanisms of germ cell specification across the metazoans: epigenesis and preformation. Development. 2003;130(24):5869-84.

53. Tsunekawa N, Naito M, Sakai Y, Nishida T, Noce T. Isolation of chicken vasa homolog gene and tracing the origin of primordial germ cells. Development. 2000;127(12):2741-50.

54. Lee HC, Choi HJ, Lee HG, Lim JM, Ono T, Han JY. DAZL expression explains origin and central formation of primordial germ cells in chickens. Stem Cells Dev. 2016;25(1):68-79.

Ready to submit your research? Choose BMC and benefit from:

- fast, convenient online submission

- thorough peer review by experienced researchers in your field

- rapid publication on acceptance

- support for research data, including large and complex data types

- gold Open Access which fosters wider collaboration and increased citations

- maximum visibility for your research: over $100 \mathrm{M}$ website views per year

At $\mathrm{BMC}$, research is always in progress.

Learn more biomedcentral.com/submissions 